\title{
Validation of the GSFQ, a self-administered symptom frequency questionnaire for patients with gastroesophageal reflux disease
}

\author{
Pierre Paré MD FRCPC FACG ${ }^{1}$, François Meyer MD DSc ${ }^{2}$, David Armstrong MA MB BChir FRCP FRCPC ${ }^{3}$, \\ Myron Pyzyk $\mathrm{MS}^{4}$, Dan Pericak MMath ${ }^{5}$, Ron Goeree $M A^{6}$
}

P Paré, F Meyer, D Armstrong, M Pyzyk, D Pericak, $\mathrm{R}$ Goeree. Validation of the GSFQ, a self-administered symptom frequency questionnaire for patients with gastroesophageal reflux disease. Can J Gastroenterol 2003;17(5):307-312.

BACKGROUND: Although the diagnosis of gastroesophageal reflux disease (GERD) is based primarily on symptoms experienced by a patient, relatively little attention has been paid to the development and validation of self-administered questionnaires specific to GERD symptoms. The present article presents the validation of the short, selfadministered GERD Symptom Frequency Questionnaire (GSFQ).

METHODS: Patients with GERD participating in a randomized clinical trial comparing pantoprazole and nizatidine were asked to complete the GSFQ together with validated instruments for measurement of health-related quality of life (Medical Outcome Study Short Form 12) and gastrointestinal symptoms (Gastrointestinal Symptom Rating Scale). Completion of the GSFQ, Medical Outcome Study Short Form 12 and Gastrointestinal Symptom Rating Scale took place upon entry into the trial (baseline) and during the trial (days 7 and 28). Endoscopy was performed at baseline and after 28 days. Cronbach alpha was used to assess the internal consistency of the questionnaire. The test-retest reliability of the GSFQ was examined by the intraclass correlation coefficient among the 36 patients with stable GERD symptoms between day 7 and day 28. Construct validity was assessed by comparing the GSFQ with previously validated instruments. Known group validity was determined by comparing GSFQ scores across groups of patients known to differ clinically. Responsiveness to change was assessed by the Guyatt's statistic.

RESULTS: Two hundred twenty-one patients formed the study baseline group. The analysis demonstrated that the GSFQ questionnaire had excellent psychometric properties shown by the high internal consistency (Cronbach alpha 0.84); that the test-retest reliability was satisfactory (intraclass correlation coefficient 0.64 ); that there was good evidence that the GSFQ indeed measured what it was intended to measure (validity); and that the GSFQ was highly responsive to change (Guyatt's statistic 1.48).

DISCUSSION: The GSFQ is a short, self-administered, easy to use, GERD-specific questionnaire which should be considered as a useful assessment tool in the evaluation of patients with GERD and in the assessment of treatment outcomes.

\author{
Validation du QFSR, un questionnaire \\ autoadministré sur la fréquence des \\ symptômes pour les patients atteints d'un \\ reflux gastro-esophagien pathologique
}

HISTORIQUE : Bien que le diagnostic de reflux gastro-œesophagien pathologique (RGOP) soit surtout fondé sur les symptômes du patient, on porte relativement peu d'attention à l'élaboration et à la validation de questionnaires autoadministrés propres aux symptômes de RGOP. Le présent article décrit la validation du questionnaire sur la fréquence des symptômes de RGOP (QFSR).

MÉTHODOLOGIE : Les patients atteints de RGOP qui participaient à un essai clinique aléatoire comparant le pantoprazole et la nizatidine ont été invités à remplir le QFSR ainsi que des outils validés pour mesurer la qualité de vie reliée à la santé (formulaire court 12 de l'étude sur les issues médicales) et les symptômes gastro-intestinaux (échelle d'évaluation des symptômes gastro-intestinaux). Les réponses au QFSR, au formulaire court 12 sur l'étude des issues médicales et à l'échelle d'évaluation des symptômes gastro-intestinaux a eu lieu à l'enrôlement (base de référence) et pendant l'essai (jours 7 et 28). Une endoscopie a été effectuée à la base de référence et après 28 jours. Le coefficient alpha de Cronbach a été utilisé pour évaluer la cohérence interne du questionnaire. La fiabilité de test-retest du QFSR a été examinée au moyen du coefficient de corrélation intraclasse auprès de 36 patients présentant des symptômes de RGOP stables entre le jour 7 et le jour 28. La validité conceptuelle a été évaluée en comparant le QFSR à des outils déjà validés. La validité des groupes connus a été déterminée en comparant les cotes du QFSR entre les groupes de patients dont la présentation clinique était différente. La réactivité au changement a été évaluée à l'aide des statistiques de Guyatt. RÉSULTATS : Deux cent vingt et un patient ont formé le groupe de base de référence de l'étude. L'analyse a démontré que le QFSR était doté d'excellentes propriétés psychométriques en raison de sa cohérence interne élevée (coefficient alpha de Cronbach de 0,84), que selon les éléments probants, le QFSR mesurait bel et bien ce qu'il était conçu pour mesurer (validité) et que le QFSR était hautement réactif au changement (statistiques de Guyatt de 1,48).

DISCUSSION : Le QFSR est un questionnaire autoadministré court, facile à remplir et propre au RGOP qui devrait être envisagé comme outil d'évaluation utile pour apprécier les patients atteints de RGOP et les issues des traitements.

Key Words: Gastroesophageal reflux disease; Health-related quality of life; Heartburn

${ }^{1}$ Division of Gastroenterology, Centre Hospitalier Affilié Universitaire de Québec and Laval University; ${ }^{2}$ Department of Social and Preventive Medicine, Laval University, Quebec City, Quebec; ${ }^{3}$ Division of Gastroenterology, McMaster University, Hamilton; ${ }^{4}$ Solvay Pharma Inc, Scarborough; ${ }^{5}$ Innovus Research Inc, Burlington; ${ }^{6}$ Department of Clinical Epidemiology and Biostatistics, McMaster University and Centre for Evaluation of Medicines, St Joseph's Hospital, Hamilton, Ontario

Correspondence and reprints: Dr Pierre Paré, Centre Hospitalier Affilié Universitaire de Québec-Hôpital St-Sacrement, Division of Gastroenterology, 1050 Chemin Ste-Foy, Quebec City, Quebec G1S 4L8. Telephone 418-682-7646, fax 418-682-7855,

e-mail pierre.pare@cha.quebec.qc.ca 
astroesophageal reflux disease (GERD) is a common condi$\mathbf{J}_{\text {tion characterized by heartburn, that is defined as a burning }}$ feeling rising from the stomach or lower chest towards the neck (1). Although the presence of esophageal erosions is highly specific for GERD, many patients with GERD have no evidence of erosive esophagitis. Endoscopy is rather insensitive for the diagnosis and follow-up of GERD. Therefore, the diagnosis of GERD relies primarily on symptoms reported by patients either spontaneously or in response to physicians' queries (2).

Little attention has been paid to the development and validation of structured self-administered questionnaires specific for GERD symptoms $(3-7)$. In some instances $(3,6)$ the Gastrointestinal Symptom Rating Scale (GSRS) has been used. However, there are only two items relevant to GERD in this instrument (8). To date, several symptom questionnaires specific to GERD have been proposed $(4,5,7)$; however, their use may be limited because of their length and complexity. Furthermore, an instrument highly responsive to treatment would be useful for assessing changes in GERD patients.

The authors have developed a short, simple, self-administered GERD symptom frequency questionnaire (GSFQ) and asked patients with GERD who participated in a randomized trial comparing pantoprazole and nizatidine to complete this questionnaire together with other validated instruments during the course of the trial (9). The information collected in this study was used to validate this new GERD questionnaire.

\section{METHODS}

This was a multicentre, double-blind parallel group, randomized study. It was undertaken to compare pantoprazole $40 \mathrm{mg}$ once daily and nizatidine $150 \mathrm{mg}$ twice daily in the management of patients presenting with heartburn as the primary symptom of GERD in 16 centres across Canada. Patients were eligible to participate in the trial if they reported heartburn symptoms at least four times a week during the preceding six months. Baseline data collection using self-administered questionnaires was conducted before endoscopy, randomization and initiation of treatment. The trial medication was prescribed for 28 days. Follow-up visits were scheduled at day 7 and day 28. During these visits, GERD symptoms and quality of life were assessed by the patients using the same self-administered questionnaires used at baseline. At these visits, the treating physician systematically assessed the presence of GERD symptoms, severity and degree of control using a standardized protocol. Upon completion of the trial a final endoscopy was performed. The study protocol and the results concerning treatment efficacy for the relief of heartburn symptoms and improvement of quality of life have already been presented $(9,10)$.

Three self-administered instruments were used to assess patients' quality of life, perceptions and subjective symptoms over the previous seven days. For the evaluation of general well being, a short validated instrument, the Medical Outcome Study Short Form 12 (SF-12), was selected (11). This questionnaire, which was developed as a shorter alternative to the original SF-36, was found to be comparable to the SF-36 in terms of reliability and validity (12). Analysis of the SF-12 answers produces a physical component summary score and a mental component summary score. To fully assess four domains covered by the SF-36 (physical role functioning, bodily pain, vitality and social functioning) (13), seven additional questions were taken from the SF-36 and added to the 12 items constituting the SF- 12 .
To assess the intensity of gastrointestinal symptoms (8), the GSRS, a validated 15-item questionnaire was used. The GSRS has five subscales corresponding to various gastrointestinal disorders: diarrhea, indigestion, constipation, abdominal pain and reflux syndrome. The reflux syndrome subscale, which is most pertinent for GERD patients, is based on only two items.

The GSFQ is a self-administered disease-specific instrument developed by the authors for this trial to assess the frequency of certain GERD symptoms (three items) and their effect on eating, daily activities and sleep (three items). The questionnaire was designed by the authors (PP, DA, MP, RG). The objective was to develop a simple, short, self-administered questionnaire on GERD symptom frequency and its effect on quality of life. Clinical and epidemiological expertise, experience in focus groups with GERD patients, a review of the literature and group consensus were used to develop the questionnaire. Pretesting was performed in 25 GERD patients; ease of completion was confirmed and no change in wording was recommended by these patients. This new instrument (GSFQ) is presented in Figure 1. The methods used to validate the GSFQ are presented in detail below.

\section{Scoring}

The GSFQ is composed of six questions to be answered following ordinal scales. Three questions focus on the frequency of GERD symptoms over the previous seven days. The possible answers are: all of the time, most of the time, some of the time, a little of the time and none of the time, which were coded four, three, two, one and zero, respectively. One question concerns the limitations in eating due to GERD symptoms with possible answers following the same ordinal scale. The last two questions determine the number of days in the previous week during which symptoms have interfered with daily life activities or sleep, with possible answers ranging from zero to seven. The sum of all six item scores (with possible values ranging from zero to 30 ) was divided by 0.3 to obtain an overall GSFQ score ranging from zero in the absence of GERD symptoms to 100 for severely affected patients. Weight was placed on the last two questions since these items reflect and affect specifically quality of life, whereas the first questions measure frequency of symptoms.

\section{Consistency}

Cronbach alpha, which assesses the extent to which items in a scale correlate with each other to constitute a multi-item scale, was used to determine whether all the questions in the GSFQ measure the same construct (14). In the literature, an alpha equal to 0.70 is considered acceptable. In addition, Spearman correlation coefficients between all pairs of items in the GSFQ were examined to assess whether all items were positively correlated.

\section{Reliability}

Reliability refers to the degree to which measurements are repeatable and consistently produce the same results. To evaluate the reliability of the GSFQ, all patients with stable GERD symptoms over a three week period from the follow-up visit on day 7 until the final visit on day 28 were identified among the study participants. For 36 patients, the physician's assessment of the presence, severity and control of GERD symptoms (heartburn, acid regurgitation, epigastric pain and retrosternal pain) was identical on day 7 and on day 28. The GSFQ completed by these 36 patients, before visits on days 7 and 28, were used to assess the test-retest reliability of the questionnaire by comparing the mean scores at the two visits 


\section{GASTROINTESTINAL SHORT FORM QUESTIONNAIRE (GSFQ)}

Instructions: Answer each question by checking one box. If you are unsure about how to answer a question, please give the best answer you can.

These questions are about how stomach problems have affected you during the past week:

How much of the time during the past week -

1. Have you had pain or discomfort in the upper abdomen (such as burning, bloating or fullness)?.

2. Have you had pain or discomfort in the area of the breast bone (such as heartburn, fullness or sensation of blockage)?

3. Have you been limited in eating a normal meal or in your choice of foods or beverages because of your stomach problems?

4. Do you experience a rising, spreading, burning sensation behind your breastbone (heartburn)?

$\begin{array}{ccccc}\text { All of } & \text { Most } & \text { Some } & \text { A little } & \text { None } \\ \text { the of the } & \text { of the } & \text { of the } & \text { of the } \\ \text { time time } & \text { time } & \text { time } & \text { time }\end{array}$

5. During the past week, have your normal daily activities been affected by your heartburn?

6. During the past week, has your sleep been disturbed because of your hearburn?

\section{$\square$ No \\ $\square$ Yes $\Rightarrow \quad$ If yes, how many days of normal daily activities have been affected during the past week?}

$\square$ No
$\square$ Yes $\Rightarrow \quad \begin{aligned} & \text { If yes, how many nights of } \\ & \text { your sleep have been } \\ & \text { disturbed during the past } \\ & \text { week? }\end{aligned}$

(days)

(nights)

Figure 1) Gastrointestinal Short Form Questionnaire

and by measuring the degree of agreement by an intraclass correlation coefficient (15).

\section{Validity}

The validity refers to the extent to which the instrument actually measures what it is intended to measure (16). For the validation of the GSFQ, construct validity was examined by comparing the results of the GSFQ with other previously validated questionnaires: the GSRS, SF-12 and the four dimensions of the SF-36. Convergent validity is present where scales that measure the same construct are positively correlated. Divergent validity is observed when scales that measure different constructs are weakly or negatively correlated. Known group validity was assessed by comparing the GSFQ scores across groups of patients known to differ clini- cally in the presence, severity and degree of control of GERD symptoms. For comparison, the same known group validity analyses were performed for the GSRS and the SF-12 instruments.

Responsiveness to change

Analysis of the responsiveness to change determined the extent to which GSFQ was able to detect changes in disease state over time within patients. Both clinical (heartburn) and endoscopic (esophagitis) changes were considered. The Guyatt's statistic, which is the ratio of the score change among patients with improvement over the standard deviation of the score change among those with no improvement, was the primary tool used to assess responsiveness to change (17). For comparison, the same analyses were performed for the GSRS and the SF-12 scores. 


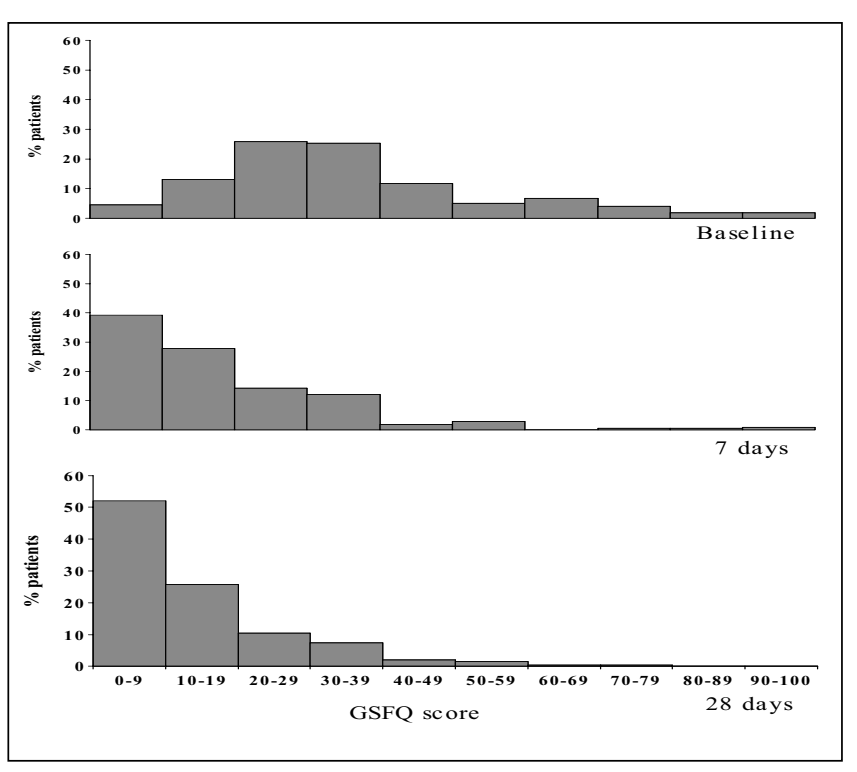

Figure 2) Distribution of Gastroesophageal Reflux Disease Symptom Frequency Questionnaire (GSFQ) scores respectively at baseline, after seven days and after 28 days of treatment

\section{RESULTS}

Baseline information was available for 221 patients, (110 patients randomized to nizatidine and 111 patients randomized to pantoprazole) aged between 19 and 76 years (median 48 years) of which $54 \%$ were men, $60 \%$ were employed, $22 \%$ and $42 \%$ were respectively current and past smokers, and $66 \%$ consumed some alcohol. Heartburn symptoms were reported by $99 \%$ of subjects during the day and by $68 \%$ during the night. Severe heartburn was present in 33\% of patients during the day and in $21 \%$ during the night. The initial endoscopy showed evidence of grade one esophagitis for $38 \%$ of patients and of grade two or three for $22 \%$ of patients according to the SavaryMiller classification system (17). Evidence of Helicobacter pylori infection was seen in $17 \%$ of the patients (9). Complete GSFQ data were available for 209 and 202 subjects respectively at the follow-up visit after seven days of treatment and at the final visit after 28 days of treatment. The distribution of GSFQ scores at baseline, after seven and after 28 days of treatment are shown in Figure 2. The mean score decreased from 34.9 at baseline, to 15.7 on day 7 , and to 11.4 on day 28 .

The score obtained for each of the six questions constituting the GSFQ were all positively intercorrelated (Table 1). The three questions on symptom frequency (pain in upper abdomen, pain in area of breast bone and burning sensation) were strongly intercorrelated (correlation coefficients between 0.47 and 0.51). All items were strongly correlated with the overall GSFQ score (correlation coefficients between 0.57 and 0.71). The Cronbach alpha was 0.84 at baseline and 0.88 after seven or 28 days of treatment. These values are above the desirable level of 0.70 for Cronbach alpha, clearly indicating that the internal consistency of the GSFQ was excellent.

To study the test-retest reliability of the GSFQ, 36 patients with stable GERD symptoms over the three week period from day 7 until day 28 were selected. The mean GSFQ scores were nearly identical: 19.9 (SD 16.1) on day 7 and 19.8 (SD 15.6) on day 28 . The intraclass correlation coefficient was 0.64 , suggesting that the reliability of the instrument was good. Correlation coefficients were calculated between the GSFQ score and other well established scales: the five subscales and the overall GSRS score, and the SF-12 physical and mental summaries (Table 2). Higher correlations were observed with scales measuring the same construct, in particular the reflux syndrome of the GSRS (convergent validity) while lower correlations were found for scales measuring different constructs such as the diarrhea or constipation syndromes of the GSRS (divergent validity). Correlations of similar magnitude were observed for all dimensions of quality of life as measured by the SF-12 and SF-36 instruments. The correlations between the GSFQ and the four dimensions of the SF-36 were respectively -0.32 for physical role and bodily pain, -0.29 for vitality and -0.25 for social functioning. The inverse associations are due to the fact that the SF scales have higher values for good health and lower values for poor quality of life.

Patients were categorized into groups based on the physician's assessment of symptom presence and severity at baseline. The respective mean values of GSFQ, GSRS and SF-12 physical component summaries are presented for each category of these variables in Table 3. There was no association between the severity of GERD symptoms and the SF-12 mental component summary. The SF-12 physical component summary was not sensitive enough to reflect severity of GERD symptoms, except for heartburn and acid regurgitation during the day. On the other hand, both GSFQ and GSRS scores displayed increasing values with increasing severity of GERD symptoms. The relative range of scores across categories of symptom severity was greater for GSFQ than for GSRS. In addition, the severity of GERD symptoms was reflected in a consistent dose response manner for GSFQ scores. Therefore, the known group validity of the new GSFQ questionnaire was at least as good as that of the validated GSRS. There was no

TABLE 1

Spearman correlation coefficients between individual question scores and overall score of the GSFQ among 221 patients with GERD symptoms at baseline

\begin{tabular}{|c|c|c|c|c|c|c|}
\hline & $\begin{array}{l}\text { Pain in upper } \\
\text { abdomen }\end{array}$ & $\begin{array}{l}\text { Pain behind } \\
\text { breast bone }\end{array}$ & $\begin{array}{l}\text { Limitation } \\
\text { in eating }\end{array}$ & $\begin{array}{l}\text { Burning } \\
\text { sensation }\end{array}$ & $\begin{array}{c}\text { Daily activities } \\
\text { affected }\end{array}$ & $\begin{array}{c}\text { Sleep } \\
\text { disturbed }\end{array}$ \\
\hline Pain in upper abdomen & - & & & & & \\
\hline Pain behind breast bone & 0.47 & - & & & & \\
\hline Limitation in eating & 0.30 & 0.36 & - & & & \\
\hline Burning sensation & 0.47 & 0.51 & 0.43 & - & & \\
\hline Daily activities affected & 0.19 & 0.21 & 0.38 & 0.21 & - & \\
\hline Sleep disturbed & 0.18 & 0.19 & 0.31 & 0.25 & 0.39 & - \\
\hline Overall GSFQ score & 0.57 & 0.62 & 0.71 & 0.65 & 0.62 & 0.65 \\
\hline
\end{tabular}

GERD Gastroesophageal reflux disease; GSFQ GERD symptom frequency questionnaire 
TABLE 2

Spearman correlation coefficients between GSFQ overall score and other validated scales among 221 patients with GERD symptoms at baseline

\begin{tabular}{lcl}
\hline & $\begin{array}{c}\text { Correlation } \\
\text { coefficient }\end{array}$ & \multicolumn{1}{c}{ P } \\
\hline GSRS, diarrhea syndrome & 0.12 & 0.09 \\
GSRS, indigestion syndrome & 0.34 & 0.0001 \\
GSRS, constipation syndrome & 0.09 & 0.21 \\
GSRS, abdominal pain & 0.45 & 0.0001 \\
GSRS, reflux syndrome & 0.52 & 0.0001 \\
GSRS overall score & 0.43 & 0.0001 \\
SF-12, physical component summary & -0.30 & 0.0001 \\
SF-12, mental component summary & -0.29 & 0.0001
\end{tabular}

GERD Gastroesophageal reflux disease; GSFQ GERD symptom frequency questionnaire; GSRS Gastrointestinal symptom rating scale; SF-12 Medical Outcome Study Short Form 12

relationship between degree of esophagitis at endoscopy and scores for any of the instruments studied. The mean GSFQ scores were 33.4, 36.5, and 34.6, respectively, for patients without esophagitis, and for those with reflux esophagitis grade 1 and for those with grade 2 or 3 esophagitis $(\mathrm{P}=0.59)$. Similarly, the mean GSFQ scores were almost identical in patients with $H$ pylori infection (33.8) and in those with no evidence of $\mathrm{H}$ pylori infection (35.2, $\mathrm{P}=0.69)$.

The Guyatt's statistic was used to assess responsiveness of the GSFQ and the other self-administered instruments to changes over a four-week period in heartburn symptoms and to changes in the degree of esophagitis (Table 4). It is usually con- sidered that values greater than 1.0 are obtained for instruments highly responsive to changes. The GSFQ was more sensitive to changes in heartburn (Guyatt's statistic 1.48) than the GSRS (Guyatt's statistic 0.95). It is interesting to note that both the GSFQ and the GSRS were also responsive to changes in esophagitis, even though these instruments did not reflect the degree of esophagitis at baseline.

\section{DISCUSSION}

The GSFQ is a short, self-administered, easy to use GERDspecific questionnaire. The present study provides evidence that this new instrument is internally consistent, reliable and valid. In addition, this new instrument is highly responsive to change (Guyatt's statistic 1.48), which makes it very useful for assessing changes in GERD patients.

A few authors have proposed disease-specific questionnaires to measure the severity of GERD and their consequences on quality of life. The GSRS has been formally developed and validated but lacks specificity in assessing GERD symptoms. This is mainly because only two of its 15 items deal with heartburn and acid regurgitation (8). The Ulcus Esophagitis Subjective Symptoms (UESS) was developed by Dimenäs and colleagues (3) to quantify the symptoms of patients with peptic ulcer and esophagitis. The UESS comprises nine items regrouped into four dimensions, including reflux discomfort (based on two questions). Responsiveness to change after treatment was observed for reflux discomfort of the UESS and for the dyspeptic syndrome of the GSRS (Guyatt's statistic respectively 0.68 and 0.43 ) (3). Rush et al (19) used a heartburn specific quality

\section{TABLE 3}

Mean of GSFQ, GSRS and SF-12 physical summary scores according to presence and severity of GERD symptoms during the day and during the night among the 200 patients who completed all three questionnaires at baseline.

\begin{tabular}{|c|c|c|c|c|c|c|c|c|}
\hline & \multirow[t]{2}{*}{$\begin{array}{l}\text { Severity of } \\
\text { symptom }\end{array}$} & \multirow[t]{2}{*}{$\begin{array}{c}\text { Number of } \\
\text { patients }\end{array}$} & \multicolumn{2}{|c|}{ GSFQ } & \multicolumn{2}{|c|}{ GSRS } & \multicolumn{2}{|c|}{ SF-12 physical } \\
\hline & & & Mean & $\mathbf{P}$ & Mean & $\mathbf{P}$ & Mean & $\mathbf{P}$ \\
\hline \multirow[t]{4}{*}{ Heartburn, daytime } & Absent & 2 & 18.5 & 0.0001 & 1.8 & 0.0002 & 46.7 & 0.75 \\
\hline & Mild & 35 & 27.1 & & 2.4 & & 49.2 & \\
\hline & Moderate & 98 & 32.7 & & 2.7 & & 48.9 & \\
\hline & Severe & 65 & 40.9 & & 3.0 & & 47.6 & \\
\hline \multirow[t]{4}{*}{ Heartburn, night-time } & Absent & 65 & 28.0 & 0.0001 & 2.7 & 0.35 & 48.4 & 0.76 \\
\hline & Mild & 27 & 30.6 & & 2.6 & & 49.3 & \\
\hline & Moderate & 67 & 35.5 & & 2.7 & & 48.9 & \\
\hline & Severe & 41 & 44.6 & & 2.9 & & 47.4 & \\
\hline \multirow[t]{4}{*}{ Acid regurgitation, daytime } & Absent & 55 & 30.4 & 0.0001 & 2.4 & 0.0001 & 49.7 & 0.04 \\
\hline & Mild & 46 & 30.9 & & 2.6 & & 49.6 & \\
\hline & Moderate & 64 & 32.9 & & 2.8 & & 48.6 & \\
\hline & Severe & 35 & 47.3 & & 3.3 & & 45.0 & \\
\hline \multirow[t]{4}{*}{ Acid regurgitation, night-time } & Absent & 122 & 29.5 & 0.0001 & 2.6 & 0.0004 & 49.1 & 0.08 \\
\hline & Mild & 15 & 32.9 & & 2.4 & & 51.4 & \\
\hline & Moderate & 44 & 38.1 & & 3.0 & & 47.5 & \\
\hline & Severe & 19 & 57.2 & & 3.3 & & 44.8 & \\
\hline \multirow[t]{4}{*}{ Epigastric pain, daytime } & Absent & 101 & 30.0 & 0.0009 & 2.5 & 0.0001 & 49.1 & 0.001 \\
\hline & Mild & 28 & 34.7 & & 2.5 & & 52.9 & \\
\hline & Moderate & 57 & 38.0 & & 3.0 & & 46.2 & \\
\hline & Severe & 14 & 48.8 & & 3.6 & & 44.9 & \\
\hline \multirow[t]{4}{*}{ Epigastric pain, night-time } & Absent & 146 & 31.2 & 0.0001 & 2.6 & 0.0007 & 49.0 & 0.33 \\
\hline & Mild & 14 & 33.5 & & 2.7 & & 49.3 & \\
\hline & Moderate & 27 & 43.5 & & 2.8 & & 47.1 & \\
\hline & Severe & 13 & 50.8 & & 3.6 & & 45.2 & \\
\hline
\end{tabular}

GERD Gastroesophageal reflux disease; GSFQ GERD symptom frequency questionnaire; GSRS Gastrointestinal symptom rating scale; SF-12 Medical Outcome Study Short Form 12 
TABLE 4

Guyatt's statistic for responsiveness of GERD symptom frequency questionnaire (GSFQ) and other validated instruments to changes in heartburn symptoms and changes in esophagitis over a 28 day period

\begin{tabular}{lcccccc}
\hline & Score change & Heartburn & SD & Guyatt's statistic & Score change & Esophagitis \\
SD & Guyatt's statistic \\
\hline GSFQ & 25.1 & 16.9 & 1.48 & 24.9 & 16.8 & 1.48 \\
GSRS & 0.77 & 0.81 & 0.95 & 0.74 & 0.74 & 1.00 \\
SF-12 physical component summary & 1.79 & 9.16 & 0.20 & 2.37 & 7.80 & 0.30 \\
SF-12 mental component summary & 2.18 & 11.1 & 0.20 & 2.17 & 10.2 & 0.21 \\
\hline
\end{tabular}

This statistic is the ratio of the score change among patients with improvement over the standard deviation (SD) of the score change among those with no improvement. GERD Gastroesophageal reflux disease; GSRS Gastrointestinal symptom rating scale; SF-12 Medical outcome study short form 12

of life questionnaire comprising 12 items but responsiveness to change was not formally evaluated. Velanovich et al (4) developed a 10-item GERD questionnaire, the GERD-HealthRelated Quality of Life (GERD-HRQL), and tested it in a clinical series of 72 patients. This instrument was not officially validated, but the authors reported that it was sensitive to change. Colwell et al (5) developed a 57-item health-related quality of life questionnaire for GERD patients. The questionnaire included the SF-12 as a generic instrument plus GERDtargeted measures: symptom frequency, bothersomeness, problems related to activities, sleep and work, overall quality of life and satisfaction with the treatment. The GERD symptom subscale was the most responsive of all subscales with a Guyatt's statistic of 0.70 . Wiklund et al $(20,21)$ developed a disease-specific quality of life instrument (QOLRAD) addressing patients concerns with GERD or with dyspepsia. The questionnaire includes 25 items assessing five distinct problems: emotional distress, sleep disturbance, problems with food and drink, limitations in physical and social functioning and lack of vitality. All QOLRAD dimensions were more strongly correlated with the SF-36 physical and mental summary scores than with the reflux subscale of the GSRS. The QOLRAD has excellent psychometric properties, including good responsiveness to change (21). Allen et al (7) proposed a short disease-

\section{REFERENCES}

1. Thompson AB, Chiba N, Armstrong D, Tougas G, Hunt RH. The second Canadian Gastroesophageal Reflux Disease consensus: Moving toward to new concepts. Can J Gastroenterol 1998;12:551-6.

2. Carlsson R, Dent J, Bolling-Sternevald E, et al. The usefulness of a structured questionnaire in the assessment of symptomatic gastroesophageal reflux disease. Scand J Gastroenterol 1998;33:1023-9.

3. Dimenäs E, Glise H, Hallerbäck B, Hernqvist H, Svedlund J, Wiklund I. Quality of life in patients with upper gastrointestinal symptoms: An improved evaluation of treatment regimens? Scand J Gastoentreol 1993;28:681-7.

4. Velanovich V, Karmy-Jones R. Measuring gastroesophageal reflux disease: Relationship between the health-related quality of life score and physiologic parameters. Am Surgeon 1998;64:649-53.

5. Colwell HH, Mathias SD, Pasta DJ, Henning JM, Hunt RH. Development of a health-related quality of life questionnaire for individuals with gastroesophageal reflux disease: A validation study. Dig Dis Sci 1999;44:1376-83.

6. Kaplan-Machlis B, Speigler GE, Revicki DA. Health-related quality of life in primary care patients with gastroesophageal reflux disease. Ann Pharmacother 1999:33:1032-6.

7. Allen CJ, Parameswaran K, Belda J, Anvari M. Reproducibility, validity, and responsiveness of a disease-specific symptom questionnaire for gastroesophageal reflux disease. Dis Esophagus 2000;13:265-70.

8. Svedlund J, Sjödin I, Dotevall G. GSRS - A clinical rating scale for gastrointestinal symptoms in patients with irritable bowel syndrome and peptic ulcer disease. Dig Dis Sci 1988;33:129-34.

9. Armstrong D, Paré P, Pericak D, Pyzyk M, and the Canadian Pantoprazole GERD Study Group. Symptom relief in gastroesophageal reflux disease: A randomized, controlled comparison of Pantoprazole and Nizatidine in a mixed patient population with erosive esophagitis or endoscopy-negative reflux disease. Am J Gastroenterol 2001;96:2849-57.

10. Paré P, Armstrong D, Pericak D, Pyzyk M. Significant and rapid HRQoL specific symptom questionnaire for patients with GERD. Six specific symptoms of GERD were scored as a product of severity (zero to three) and frequency (zero to four). In 300 patients with GERD treated by laparoscopic fundoplication, the Guyatt's statistic measuring responsiveness to change before and six months after surgery was 1.0.

\section{CONCLUSIONS}

The GSFQ is a new self-administered instrument for use with GERD patients, that is short, simple, and easy to use. The psychometric properties of the GSFQ suggest that this new instrument is well suited to GERD patients in therapeutic clinical trials because it is specific and sensitive. Moreover, the GSFQ is highly responsive to change. Indicators such as Cronbach alpha for internal consistency or Guyatt's statistic for responsiveness to change have absolute thresholds. The high values observed for these two statistics in our study indicate that the GSFQ is excellent in absolute terms. Therefore, the newly validated GSFQ represents a useful tool with which to assess and follow patients with GERD disease in clinical trials.

ACKNOWLEDGEMENT: This study was supported in part by Solvay Pharma Inc and ALTANA Pharma Inc.

improvement correlates with symptom relief in GERD patients using Pantoprazole (Panto) as compared to Nizatidine (Niza). Gastroenterology 2001;120(Suppl 1):A433.

11. Ware JE, Kosinski M, Keller SD. How to score the SF-12 physical and mental health summary scales, 2nd ed. Boston: New England Medical Center, 1995.

12. Ware JE, Kosinski M, Keller SD. A 12-item short-form health survey. Construction of scales and preliminary tests of reliability and validity. Med Care 1996;34:220-33.

13. Hopman WM, Towheed T, Anastassiades T, et al. Canadian normative data for the SF-36 health survey. Canadian Multicentre Osteoporosis Study Research Group. Can Med Assoc J 2000;163:265-71.

14. Cronbach LJ. Coefficient alpha and the internal structure of tests. Psychometrika 1951;16:297-334.

15. Fleiss JL. Reliability of measurement. In: Wiley J, ed. The Design and Analysis of Clinical Experiments. New York: Wiley-Interscience, 1986:1-32.

16. McDowell I, Newell C. Measuring health: A guide to rating scales and questionnaires. New York: Oxford University Press, 1987:26-35.

17. Guyatt G, Walter S, Norman G. Measuring change over time: Assessing the usefulness of evaluative instruments. J Chron Dis 1987;40:171-8.

18. Savary M, Miller G. The Oesophagus. Handbook and Atlas of Endoscopy. Solothrun, Switzerland: Verlag Gassmann, 1978.

19. Rush DR, Stelmach WJ, Young TL, et al. Clinical effectiveness and quality of life with Ranitidine vs placebo in gastroesophageal reflux disease patients: A clinical experience network (CEN) study. J Fam Pract 1995;41:126-36

20. Wiklund IK, Junghard O, Grace E, et al. Quality of life in reflux and dyspepsia patients. Psychometric documentation of a new disease-specific questionnaire (QOLRAD). Eur J Surg Suppl 1998;583:41-9.

21. Talley NJ, Fullerton S, Junghard O, Wicklund I. Quality of life in patients with endoscopy-negative heartburn: reliability and sensitivity of diseasespecific instruments. Am J Gastroenterol 2001;96:1998-2004. 


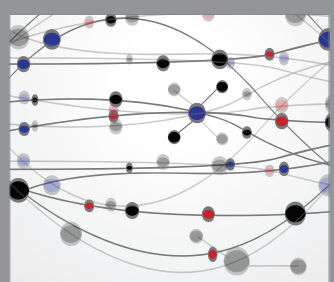

The Scientific World Journal
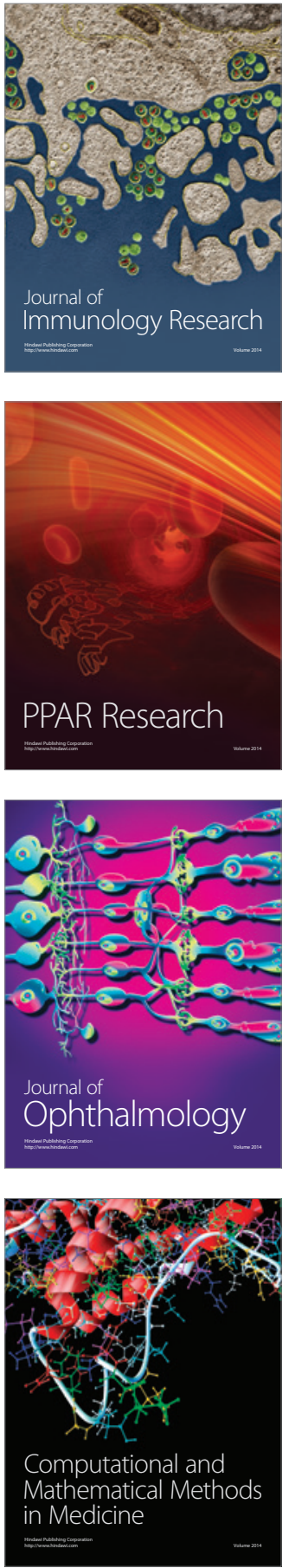

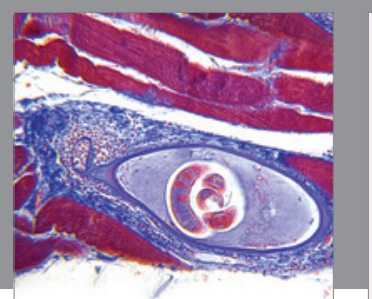

Gastroenterology Research and Practice

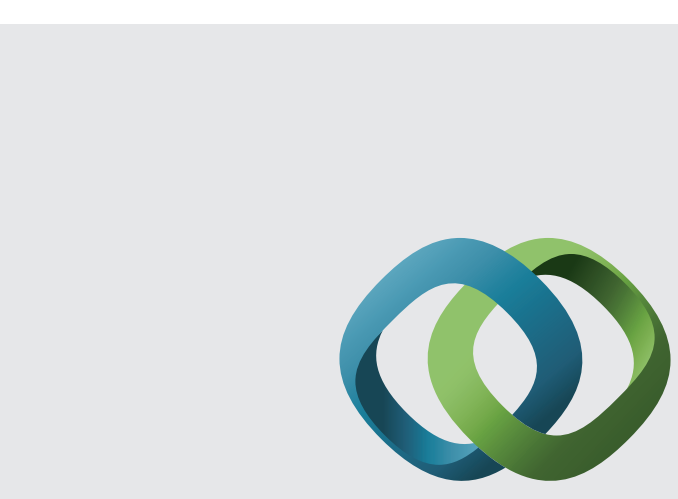

\section{Hindawi}

Submit your manuscripts at

http://www.hindawi.com
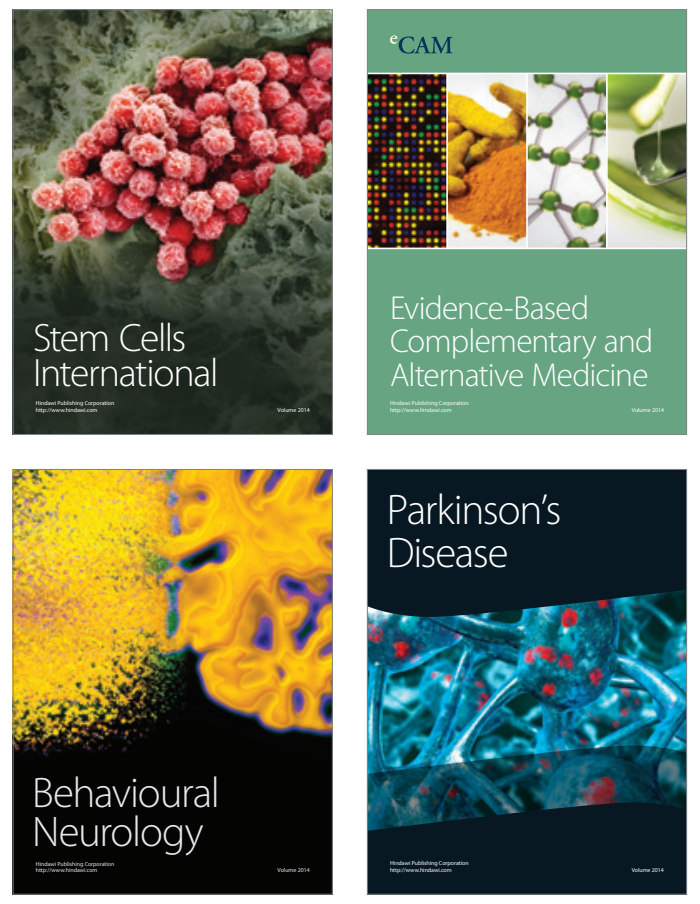
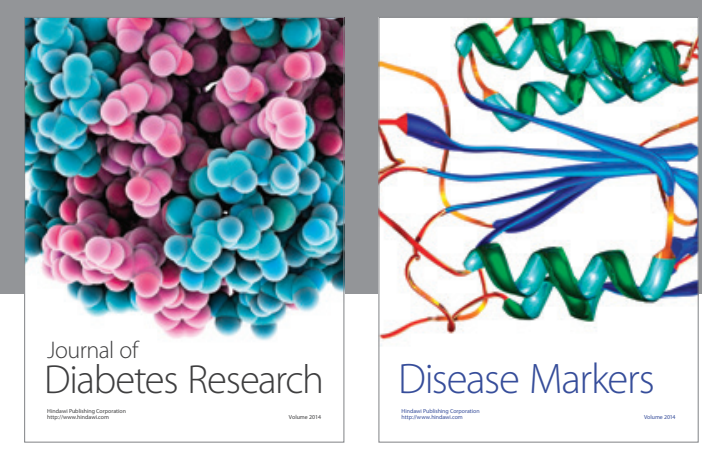

Disease Markers
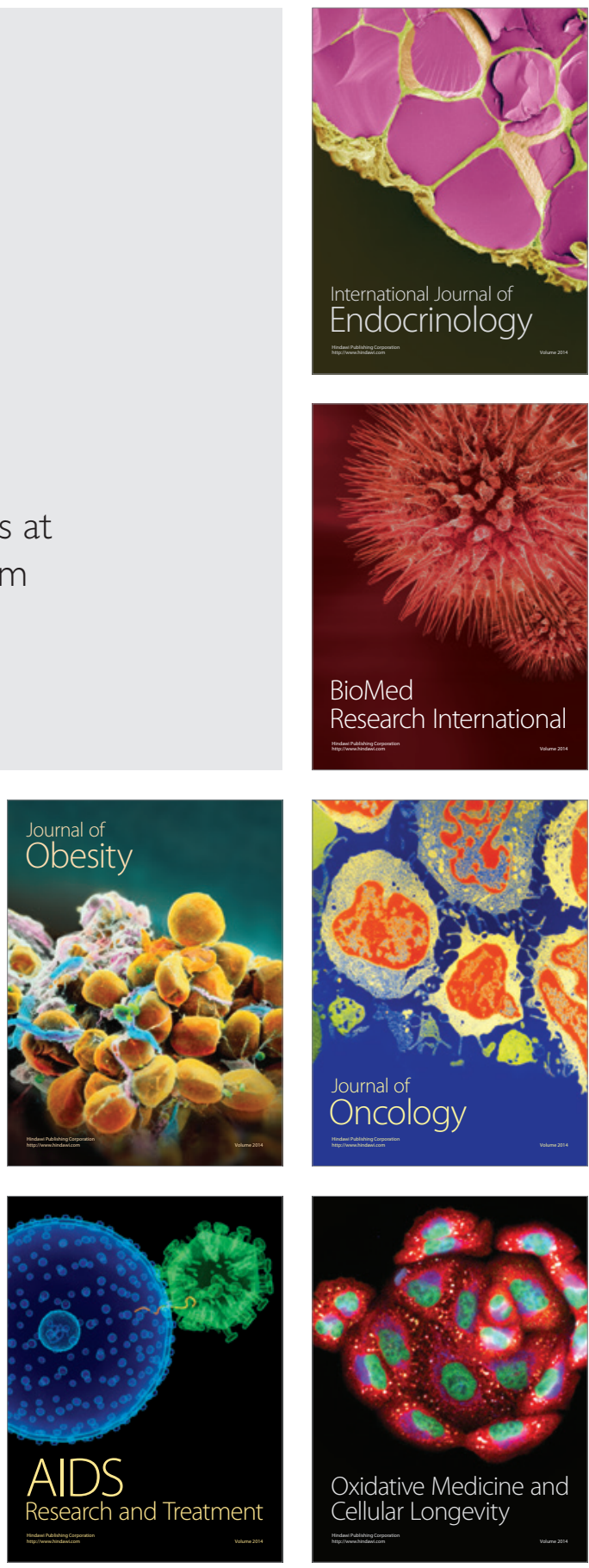